\title{
The low-affinity phosphate transporter PitA is dispensable for in vitro growth of Mycobacterium smegmatis
} Susanne Gebhard ${ }^{* 1,2,3}$, Nandula Ekanayaka ${ }^{1}$ and Gregory M Cook ${ }^{1}$

\begin{abstract}
Address: ${ }^{1}$ Department of Microbiology and Immunology, Otago School of Medical Sciences, University of Otago, PO Box 56, Dunedin, New Zealand, ${ }^{2}$ KIT Research Group 11-1, Institute of Applied Life Sciences, Karlsruhe Institute of Technology (KIT), Fritz-Haber-Weg 4, 76131 Karlsruhe, Germany and ${ }^{3}$ Current address: Department Biology I, Microbiology, Ludwig-Maximilians-University Munich, Großhaderner Str 2-4, 82152 Planegg-Martinsried, Germany
\end{abstract}

Email: Susanne Gebhard* - susanne.gebhard@bio.lmu.de; Nandula Ekanayaka - nandula_padmaperuma@hotmail.com; Gregory M Cook - gregory.cook@otago.ac.nz

* Corresponding author

Published: 10 December 2009

BMC Microbiology 2009, 9:254 doi:10.1 |86/147|-2/80-9-254
Received: 18 May 2009

Accepted: 10 December 2009

This article is available from: http://www.biomedcentral.com//47I-2/80/9/254

(c) 2009 Gebhard et al; licensee BioMed Central Ltd.

This is an Open Access article distributed under the terms of the Creative Commons Attribution License (http://creativecommons.org/licenses/by/2.0), which permits unrestricted use, distribution, and reproduction in any medium, provided the original work is properly cited.

\begin{abstract}
Background: Mycobacteria have been shown to contain an apparent redundancy of high-affinity phosphate uptake systems, with two to four copies of such systems encoded in all mycobacterial genomes sequenced to date. In addition, all mycobacteria also contain at least one gene encoding the low-affinity phosphate transporter, Pit. No information is available on a Pit system from a Gram-positive microorganism, and the importance of this system in a background of multiple other phosphate transporters is unclear.

Results: The aim of this study was to determine the physiological role of the PitA phosphate transporter in Mycobacterium smegmatis. Expression of pitA was found to be constitutive under a variety of growth conditions. An unmarked deletion mutant in pitA of M. smegmatis was created. The deletion did not affect in vitro growth or phosphate uptake of $M$. smegmatis. Expression of the high-affinity transporters, PstSCAB and PhnDCE, was increased in the pitA deletion strain.

Conclusion: PitA is the only low-affinity phosphate transport system annotated in the genome of M. smegmatis. The lack of phenotype of the pitA deletion strain shows that this system is dispensable for in vitro growth of this organism. However, increased expression of the remaining phosphate transporters in the mutant indicates a compensatory mechanism and implies that PitA is indeed used for the uptake of phosphate in M. smegmatis.
\end{abstract}

\section{Background}

Uptake of phosphate by bacteria most commonly occurs via two systems, the low-affinity, constitutively expressed Pit system, and the high-affinity, phosphate-starvation induced Pst system $[1,2]$. Pit systems consist of a single membrane protein, encoded by pitA or pitB, and are energized by the proton motive force [2,3]. Pst systems are multi-subunit $\mathrm{ABC}$ transporters, usually encoded by a four-gene operon, pstSCAB [1,2]. Several bacterial species also contain additional transporters for the uptake of alternative phosphorus-compounds. Examples include the Ptx and Htx systems of Pseudomonas stutzeri, which transport phosphonates, phosphite and hypophosphite $[4,5]$, and the Phn-system for the uptake of phosphonates in E. coli and several other Gram-negative bacteria [6-8]. 
Mycobacteria appear unique in that they contain several copies of high-affinity systems specific for phosphate: In the pathogenic species, such as M. tuberculosis, M. bovis and $M$. leprae, this is due to duplication of the pst genes [9]. For example, M. tuberculosis contains three different copies of $p s t S$, two copies each of $p s t C$ and $p s t A$, and one copy of pstB [10], plus a homologous gene, phoT, which has been shown to fulfill the same function as $p s t B$ in $M$. bovis [11]. Expression of all three copies of pstS under phosphate-limited conditions has been shown for $M$. bovis BCG [9], although a recent microarray analysis of phosphate-limited $M$. tuberculosis only found one of the pst-operons to be upregulated [12].

The environmental species $M$. smegmatis possesses only a single copy of the pst-operon, but it also contains a second operon, phnDCE, which encodes another phosphate-specific high-affinity transporter [13]. Furthermore, a third, as yet unidentified, high-affinity phosphate transport system may be present in M. smegmatis, because a $p h n D / p s t S$ double deletion mutant still retained phosphate uptake activity with a $\mathrm{K}_{\mathrm{m}}$-value of around $90 \mu \mathrm{M}$, which is similar to the values of the Pst and Phn systems [13].

Despite this abundance of high-affinity transporters, all mycobacterial genomes available to date also contain a pitA gene, encoding the low-affinity system, with the genome of M. tuberculosis containing a second Pit system, encoded by pitB [14]. The present study was directed at investigating the role of the low-affinity phosphate transporter in a bacterium containing at least two high-affinity systems, using the model of M. smegmatis.

\section{Results and Discussion PitA is constitutively expressed}

Previous studies of Pit systems have focused on Gramnegative bacteria, where pitA expression is independent of phosphate concentrations [1,15], while pitB of E. coli and the pit-like gene of Sinorhizobium meliloti are repressed at low phosphate concentrations [16,17]. To study the expression of $M$. smegmatis pitA, a low-copy number transcriptional pitA-lacZ fusion (pAH1) was introduced into wild-type $M$. smegmatis. The resulting strain had $\beta$-galactosidase activities of about 135 Miller Units (MU), both when grown in ST medium containing $100 \mathrm{mM}$ phosphate and after $2 \mathrm{~h}$ starvation in phosphate-free ST medium (Figure 1). Pit systems of Gram-negatives recognize a metal-phosphate complex $\left(\mathrm{MeHPO}_{4}\right)$ as substrate $[18,19]$. It was therefore possible that expression of $M$. smegmatis pitA was regulated by the availability of such $\mathrm{MeHPO}_{4}$ complexes, free divalent cations (e.g. $\mathrm{Mg}^{2+}$ ) or $\mathrm{pH}$, as the latter influences the distribution of the different phosphate species in solution [19]. We tested the pitA-lacZ reporter strain after $2 \mathrm{~h}$ incubation in $\mathrm{Mg}^{2+}$-free ST medium, exposure to $5 \mathrm{mM}$ EDTA, or incubation in ST

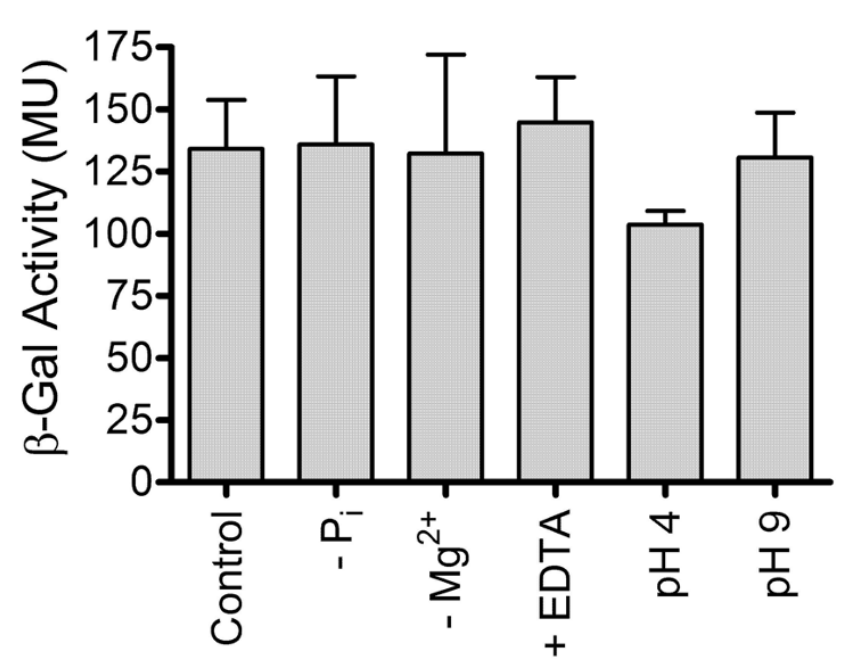

Figure I

Expression of a transcriptional pitA-lacZ fusion construct in $M$. smegmatis. Wild-type $M$. smegmatis harbouring the pitA-lac Z construct PAHI was grown in ST medium containing $100 \mathrm{mM}$ phosphate (Control), followed by $2 \mathrm{~h}$ starvation in phosphate-free $\left(-\mathrm{P}_{\mathrm{i}}\right)$ or $\mathrm{Mg}^{2+}$-free $\left(-\mathrm{Mg}^{2+}\right) \mathrm{ST}$ medium, or $2 \mathrm{~h}$ exposure to 5 mM EDTA (+ EDTA), $\mathrm{pH} 4$ or $\mathrm{pH}$ 9. $\beta$-Galactosidase $(\beta-\mathrm{Gal})$ activities were assayed and are expressed in Miller Units (MU). Results are the mean \pm standard deviation of three independent experiments.

medium buffered to $\mathrm{pH} 4$ or $\mathrm{pH} 9$. Under all conditions tested $\beta$-galactosidase activities were in the range between $100 \mathrm{MU}$ and $150 \mathrm{MU}$ (Figure 1). No significant differences to the control condition were observed $(p>0.05$ in a one-way ANOVA test followed by Dunnett's post-test analysis), suggesting that expression of M. smegmatis pitA was constitutive under all conditions tested.

\section{A pitA deletion mutant has no growth defect in vitro}

To determine if pitA played a role in growth and phosphate uptake of $M$. smegmatis, we next constructed an unmarked pita deletion strain by an adaptation of the two-step protocol used previously to create a double-kanamycin marked mutant of M. smegmatis [20] (Figure 2). In the first step of mutagenesis, the construct was integrated into the chromosome by growth at $40^{\circ} \mathrm{C}$. Southern hybridization analysis showed that correct integration had occurred via a cross-over event in the left flank (Figure 2B). Excision of the plasmid backbone through a second cross-over event was then selected for by growth on $10 \%$ sucrose. This second cross-over could lead either to reversion to wild-type or to deletion of the target gene. Nine colonies were screened by Southern hybridization, of which four had reverted back to the wild-type pattern, while five displayed the correct band pattern of a pitA deletion mutant (Figure 2C). One of the latter was chosen for further characterization. 
A
Delivery vector

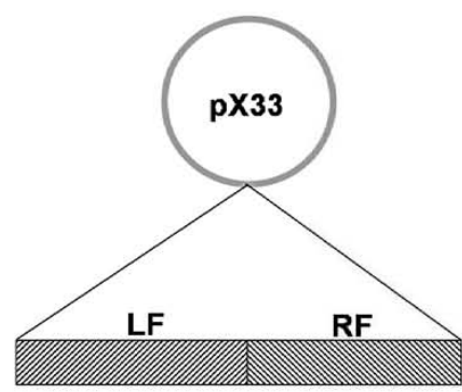

WT

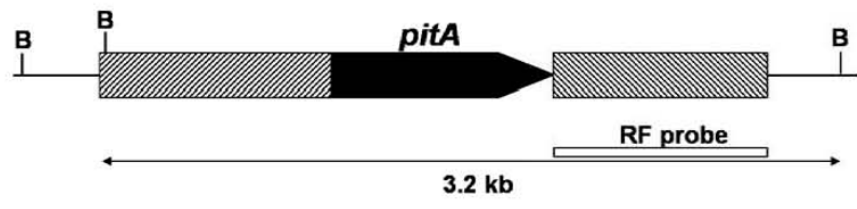

Int LF
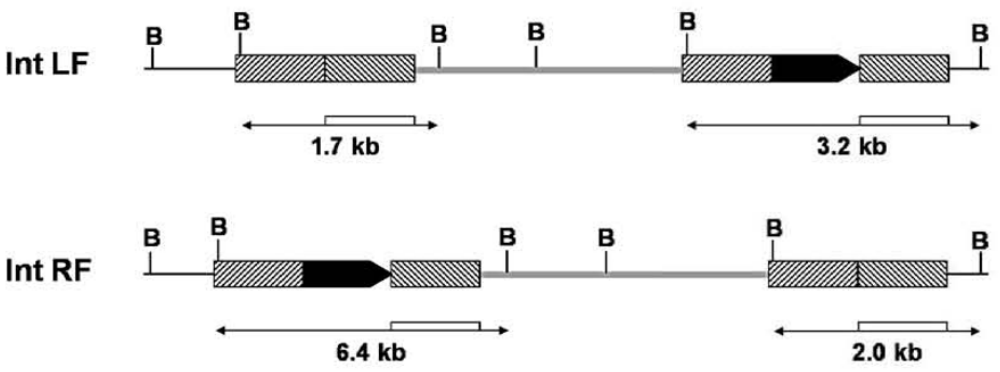

KO
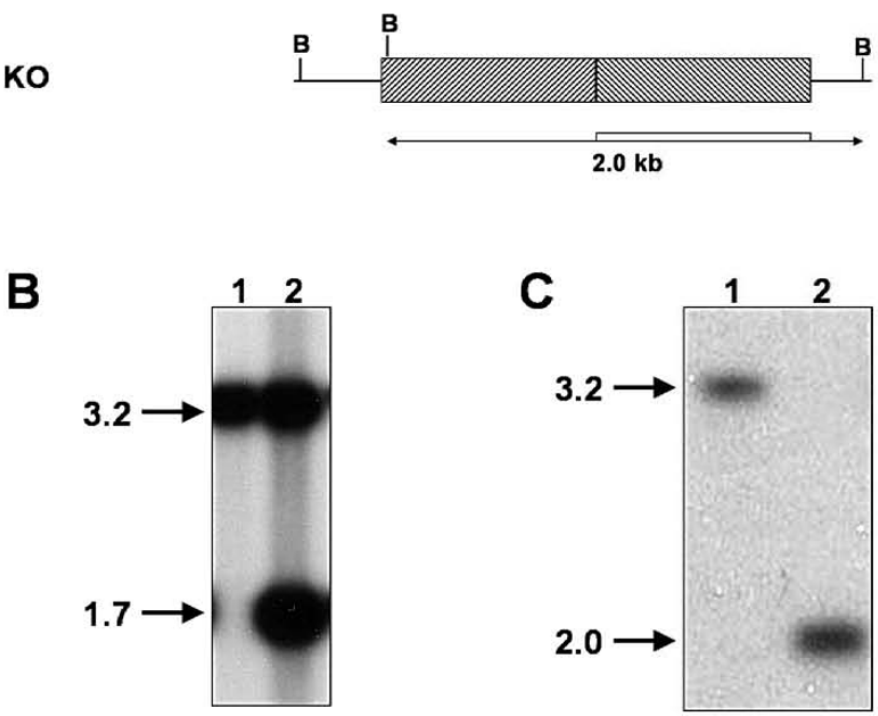

Figure 2

Construction of an unmarked pitA deletion mutant of $\mathbf{M}$. smegmatis $\mathbf{m c}^{2} \mathbf{I} 55$. A: Schematic diagram of the two-step approach for deletion of pitA. The knock-out construct consisted of two fragments flanking pitA on the left (LF) and right (RF) in pX33. Integration of the vector (thick grey line) into the chromosome (thin black line) via the left flank (Int LF) or right flank (Int RF) and subsequent deletion of pitA (KO) are shown. Restriction sites of BamHI (B) and fragment sizes as detected in Southern hybridization are indicated. Drawing not to scale. WT, wild-type. B: Southern hybridization analysis of the integration event. BamHI-digests of genomic DNA of wild-type $\mathrm{mc}^{2} \mathrm{I} 55$ (lane I) and a candidate colony (lane 2) were probed with radiolabeled right flank PCR product of the deletion construct. C: Southern hybridization analysis of pitA deletion. Analysis of wildtype $\mathrm{mc}^{2} \mathrm{I} 55$ (lane I) and the pitA deletion strain (lane 2) was performed as in panel B. Molecular masses are indicated in kb. 
Growth experiments showed no difference between wildtype and pitA mutant in LBT medium or ST medium, either under phosphate-replete conditions $(100 \mu \mathrm{M}$ to $100 \mathrm{mM}$ phosphate) or phosphate-limited conditions (10 $\mu \mathrm{M}$ or $50 \mu \mathrm{M}$ phosphate) (not shown). This characteristic of the pitA mutant is markedly different from the previously created $M$. smegmatis mutants in the high-affinity phosphate transporters, which were unable to grow in minimal medium at $10 \mathrm{mM}$ phosphate or below [13]. As mentioned above, Pit systems of Gram-negative bacteria transport a metal-phosphate complex. While no information regarding their substrate is available for Pit systems of Gram-positives, a mutant of Bacillus subtilis carrying an uncharacterized mutation in phosphate uptake was also defective in uptake of metal ions [21], suggesting an interrelation between uptake of phosphate and metals. The biological role of Pit in a bacterium with a plethora of high-affinity phosphate transporters may therefore be in uptake of divalent metal ions. To test this, we performed growth experiments in $\mathrm{Mg}^{2+}$-limited ST medium $(2 \mu \mathrm{M}$ to $2 \mathrm{mM} \mathrm{MgCl} 2$ ), but could not discern a difference between the pitA and wild-type strain (not shown). Because the distribution of $\mathrm{MeHPO}_{4}$ versus free phosphate depends on the medium $\mathrm{pH}$, with $\mathrm{MeHPO}_{4}$ being the predominant species at high $\mathrm{pH}$ values [19], it was conceivable that the physiological role of Pit is to act under conditions where most phosphate is present as $\mathrm{MeHPO}_{4}$. To simulate such a condition in vitro, we modified the ST medium to contain a high concentration of $\mathrm{MgCl}_{2}(8 \mathrm{mM})$ and low concentration of phosphate $(100 \mu \mathrm{M})$ and adjusted the $\mathrm{pH}$ to 8.5 (buffered with $100 \mathrm{mM}$ Tricine). No difference was found between the wild-type and pitA mutant strains (not shown). An E. coli pitA mutant displayed increased resistance to toxic divalent cations $\left(\mathrm{Zn}^{2+}\right.$ and $\left.\mathrm{Cd}^{2+}\right)$, due to reduced uptake of these ions [22]. The M. smegmatis pitA mutant and wild-type strain were therefore grown on solid media (ST agar, $50 \mathrm{mM}$ MES [pH 7], $1 \mathrm{mM}$ phosphate) containing 1-15 $\mathrm{mM} \mathrm{ZnSO}_{4}$ or $\mathrm{CuSO}_{4}$. Both strains were able to grow in the presence of $1 \mathrm{mM}$ of either salt, but could not grow at concentrations of $5 \mathrm{mM}$ or higher. Taken together, the data presented here suggest that either PitA of M. smegmatis does not transport $\mathrm{MeHPO}_{4}$, or that one or both of the high-affinity systems also recognize such a complex as substrate. It should be noted that no substrate specificities have been determined to date for a Pst system from a Gram-positive bacterium, or for a Phn system.

\section{The pitA mutant displays no defect in phosphate uptake} We next determined the rates and kinetics of uptake of [33P]ortho-phosphate, to assess whether the pitA deletion strain had a defect in phosphate uptake. To prevent induction of the Pst or Phn systems, cells were grown in LBT medium as described in the methods section. As shown in figure 3, maximum uptake rates were $12.9 \pm 1.6 \mathrm{nmol}$ $\mathrm{min}^{-1} \mathrm{mg}$ protein ${ }^{-1}$ for the wild-type, and $9.9 \pm 1.0 \mathrm{nmol}$

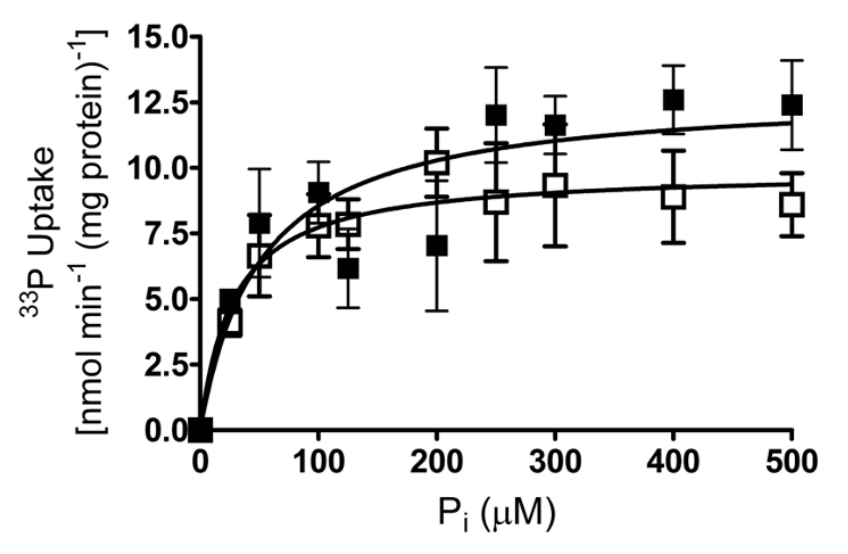

Figure 3

Kinetics of phosphate uptake. Initial uptake rates of ortho-phosphate $\left({ }^{33} \mathrm{P},>92.5 \mathrm{TBq} \mathrm{mmol}^{-1}\right)$ into LBT-grown whole cells of $M$. smegmatis $\mathrm{mc}^{2} \mathrm{I} 55$ (solid squares) and the pitA deletion strain (open squares) were measured over $60 \mathrm{~s}$ at phosphate concentrations between $25 \mu \mathrm{M}$ and $500 \mu \mathrm{M}$. Rates are expressed as nmol phosphate $\mathrm{min}^{-1} \mathrm{mg}$ mycobacterial protein extract ${ }^{-1}$, and data are shown as the mean \pm standard error of the mean from two to five independent measurements per point.

$\min ^{-1} \mathrm{mg}$ protein ${ }^{-1}$ for the pitA strain. $\mathrm{K}_{\mathrm{d}}$ values were similar between the strains, with $50.1 \pm 26 \mu \mathrm{M}$ phosphate for the wild-type and $27.9 \pm 16.4 \mu \mathrm{M}$ phosphate for the pitA strain. Slight differences in transport rates at the higher phosphate concentrations were not significant ( $p>0.2$ in unpaired, two-tailed t-test).

These kinetic parameters suggest that the rates of transport determined are due to activity of the high-affinity systems, because $K_{d}$ values of phosphate uptake under phosphatestarved (i.e. Pst and Phn systems induced) conditions were found to be between 40 and $90 \mu \mathrm{M}$ phosphate [13]. The rates of transport in the present study are about tenfold lower than those in phosphate-starved cells, consistent with the previously described 20-fold lower expression from the pst and phn promoters under these conditions [13]. PitA of M. smegmatis therefore appears to be either not active, or to have a very low activity, which cannot be detected over the background of the high-affinity systems using the assay employed here. Considering the abundance of phosphate transport systems in M. smegmatis, we hypothesized that loss of PitA is easily compensated for by increased use of the Pst and Phn systems.

\section{Deletion of pitA causes increased expression of the Pst and Phn systems}

To address the question whether the pitA deletion mutant employs increased expression of either the Pst or Phn system to compensate for the deletion, we introduced the previously created transcriptional pstS-lacZ (pSG42) and 
phnD-lacZ (pSG10) fusion constructs [13] into the pitA deletion background. As shown in figure 4, under phosphate-replete conditions the activity of both promoters was increased by about two-fold in the pitA strain. Complementation of the deletion with a single copy of pitA under control of its native promoter restored expression of $p s t S-l a c Z$ and $p h n D-l a c Z$ to wild-type levels. No differences between strains were observed in phosphate-starved cells (data not shown). These data imply that PitA is indeed used for phosphate uptake under high phosphate conditions by M. smegmatis, but that loss of this system is easily compensated for by the remaining phosphate transporters.

\section{Conclusion}

In summary, we here show that the PitA system of $M$. smegmatis is constitutively expressed under a variety of growth conditions, and that deletion of the pitA gene does not appear to affect growth or phosphate uptake in vitro. This is presumably due to compensation of the deletion by increased expression of the high-affinity phosphate transport systems, PstSCAB and PhnDCE.

The lack of phenotype of the pitA mutant under the growth conditions tested here, together with the wild-type levels of phosphate uptake in the mutant strain, raises the

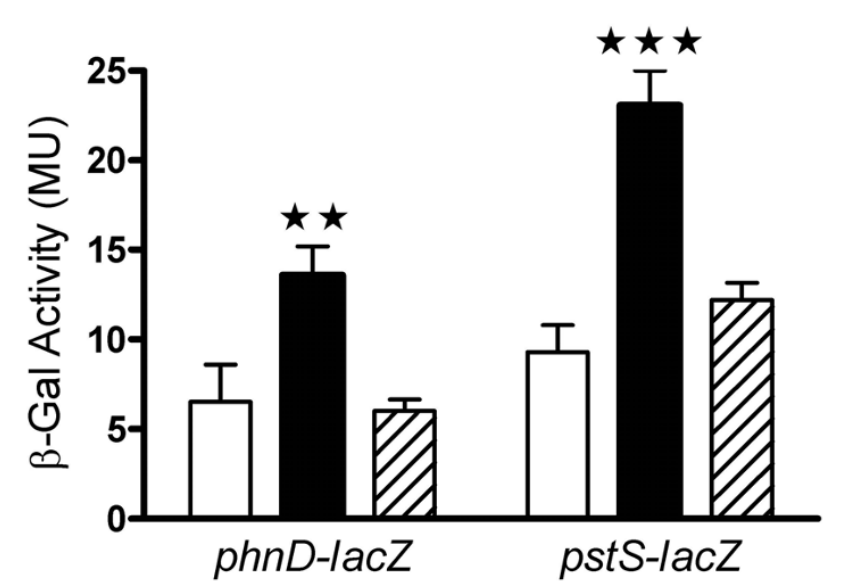

\section{Figure 4}

Expression from the pst and phn promoters in the pitA deletion background. Transcriptional phnD-lac $Z$ and pstS-lac $Z$ fusion constructs were introduced into wild-type $M$. smegmatis (open bars), the pitA deletion strain (black bars) and the pitA complemented strain (hatched bars). $\beta$-Galactosidase ( $\beta-\mathrm{Gal}$ ) activities, expressed as Miller Units (MU), were determined from cultures grown in ST medium with $100 \mathrm{mM}$ phosphate and are shown as the mean \pm standard deviation from three independent experiments. Significant differences between samples in one-way ANOVA followed by Bonferroni post-test analyses are indicated by two $(p<0.01)$ or three $(p<0.00 I)$ asterisks. question as to why mycobacteria still contain this transporter. This point is further emphasized by the presence of a functional pitA gene in M. leprae, whose genome has undergone reductions and decay to the point where the bacterium is unable to replicate outside of its host [23]. The answer may be found in the energetics of transport: Pit systems transport metal-phosphate in symport with protons at a stoichiometry of 1:1 [3], while the Pst and Phn systems are $\mathrm{ABC}$-transporters and thus likely require hydrolysis of two ATP per substrate transported [24]. Uptake of phosphate via the Pit system is therefore energetically less expensive to the cell, and this could be important under conditions where energy is limiting. However, there was no significant difference in the molar growth yield (mg [dry weight] cells/mmol of substrate consumed) between the pita deletion mutant and the wild-type when grown under carbon limitation in continuous culture at a dilution rate of $0.01 \mathrm{~h}^{-1}$ (doubling-time of $70 \mathrm{~h}$ ) (our own unpublished results). We therefore hypothesize that a phenotype for a pitA mutant of mycobacteria may well only manifest itself in vivo under conditions where the cell is exposed to multiple limitations (e.g. carbon, energy, oxygen), such as are commonly found in the intraphagosomal environment of the pathogens or the soil habitat of environmental species.

\section{Methods \\ Bacterial strains and growth conditions}

All strains and plasmids used in this study are listed in Table 1. Escherichia coli strains were grown in Luria-Bertani (LB) medium at $37^{\circ} \mathrm{C}$ with agitation (200 rpm). Mycobacterium smegmatis strain $\mathrm{mc}^{2} 155$ [25] and derived strains were routinely grown at $37^{\circ} \mathrm{C}, 200 \mathrm{rpm}$ in $\mathrm{LB}$ containing $0.05 \%(\mathrm{w} / \mathrm{v})$ Tween 80 (LBT) or in modified Sauton's (ST) medium [13]. Variations of phosphate and $\mathrm{MgCl}_{2}$ concentrations and other modifications of the ST medium are given in the text. Cells to be used as inoculum in phosphate-limited ST medium were washed once in phosphate-free medium prior to use. Starvation experiments in phosphate-free ST medium were carried out as described previously [13]. M. smegmatis transformants were grown at $28^{\circ} \mathrm{C}$ for propagation of temperature-sensitive vectors and at $40^{\circ} \mathrm{C}$ for allelic exchange mutagenesis. Selective media contained kanamycin $\left(50 \mu \mathrm{g} \mathrm{ml}^{-1}\right.$ for E. coli; $20 \mu \mathrm{g}$ $\mathrm{ml}^{-1}$ for M. smegmatis), gentamycin $\left(20 \mu \mathrm{g} \mathrm{ml}^{-1}\right.$ for E. coli; $5 \mu \mathrm{g} \mathrm{ml}^{-1}$ for M. smegmatis $)$ or hygromycin $\left(200 \mu \mathrm{g} \mathrm{ml}^{-1}\right.$ for E. coli; $50 \mu \mathrm{g} \mathrm{ml}^{-1}$ for $M$. smegmatis). Solid media contained $1.5 \%$ agar. Optical density was measured at 600 $\mathrm{nm}\left(\mathrm{OD}_{600}\right)$ using culture samples diluted in saline to bring $\mathrm{OD}_{600}$ to below 0.5 when measured in cuvettes of 1 $\mathrm{cm}$ light path length in a Jenway 6300 spectrophotometer.

\section{DNA manipulation and cloning of constructs}

All molecular biology techniques were carried out according to standard procedures [26]. Restriction or DNA mod- 
Table I: Bacterial strains, plasmids and primers used in this study

\begin{tabular}{|c|c|c|}
\hline Strain or Plasmid & Description' & Source or Reference \\
\hline \multicolumn{3}{|l|}{ E. coli } \\
\hline $\mathrm{DHIOB}$ & $\begin{array}{l}\text { F- mcrA } \Delta(m r r-h s d R M S-m c r B C) \varphi 80 d \text { lacZ } \Delta M I 5 \Delta l a c X 74 \text { deoR recAl araDI39 } \Delta(\text { ara leu)7697 } \\
\text { galU galK rpsL endAI nupG }\end{array}$ & [30] \\
\hline \multicolumn{3}{|l|}{ M. smegmatis } \\
\hline $\mathrm{mc}^{2} \mathrm{I} 55$ & Electrocompetent wild-type strain of $M$. smegmatis & [25] \\
\hline NP6 & $\mathrm{mc}^{2} \mathrm{I} 55 \Delta \mathrm{pit} A$ & This study \\
\hline NPI3 & $\mathrm{mc}^{2} 155 \Delta$ pitA carrying pCPitA; Hygr & This study \\
\hline \multicolumn{3}{|l|}{ Plasmids } \\
\hline PJEMI5 & $\begin{array}{l}\text { E. coli-mycobacteria shuttle vector for the creation of transcriptional promoter fusions to } \\
\text { lacZ; } \mathrm{Km}^{\mathrm{r}}\end{array}$ & [27] \\
\hline $\mathrm{p} \times 33$ & PPR23 [29] carrying a constitutive xylE marker; $\mathrm{Gm}^{r}$ & [13] \\
\hline PUHA267 & $\begin{array}{l}\text { E. coli vector with mycobacteriophage } L 5 \text { integrase and attP for integration into } L 5 \text { attB of } \\
\text { mycobacteria; Hygr }\end{array}$ & AgResearch, Wallaceville, NZ \\
\hline pAHI & PJEMI5 harbouring a 750 bp pitA-lacZ fusion; $\mathrm{Km}^{\mathrm{r}}$ & This study \\
\hline pPitAKO & pX33 harbouring the pitA deletion construct; $\mathrm{Gm}^{\mathrm{r}}$, Sac ${ }^{\mathrm{s}}$, ts & This study \\
\hline pCPitA & PUHA267 harbouring pitA with its native promoter; Hygr & This study \\
\hline PSGIO & PJEMI 5 harbouring a 500 bp phnD-lacZ fusion; $\mathrm{Km}^{\mathrm{r}}$ & [13] \\
\hline PSG42 & PJEMI 5 harbouring a 560 bp pstS-lacZ fusion; $\mathrm{Km}^{r}$ & [13] \\
\hline \multicolumn{3}{|c|}{ 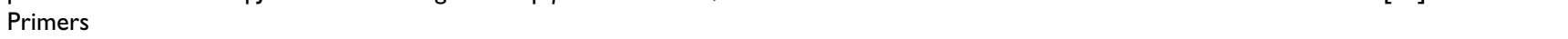 } \\
\hline PitAl & AAATTTACTAGTGTCGTCGATGGATTCTTC & This study \\
\hline PitA2 & TCAGATCAGGTGAAGTCGAAAGCAAGTG & This study \\
\hline PitA3 & CGACTTCACCTGATCTGAAGGAACGTTGA & This study \\
\hline PitA4 & AAATTTACTAGTAACGAGGGTGGTAGACAGAC & This study \\
\hline PitA5 & AAATTTGCATGCGTGAAGTCGAAAGCAAGTG & This study \\
\hline PitA6 & AAATTTGTCGTCGATGGATTCTCC & This study \\
\hline cPitAf & AAATTTAAGCTTGTCGTCGATGGATTCTCC & This study \\
\hline cPitAr & AAATTTAAGCTTACGTTCCTTCAGATCAGAC & This study \\
\hline
\end{tabular}

${ }^{\prime} \mathrm{Km}^{\mathrm{r}}$, kanamycin resistance; $\mathrm{Gm}^{\mathrm{r}}$, gentamycin resistance; $\mathrm{Hyg}^{\mathrm{r}}$, hygromycin resistance; Sacs, sucrose sensitivity; ts, temperature sensitivity. Primer sequences are given in the 5'-3' direction; restriction sites included in the primer sequences are underlined.

ifying enzymes and other molecular biology reagents were obtained from Roche Diagnostics or New England Biolabs. Genomic DNA of M. smegmatis was isolated as described previously [13]. All primer sequences are listed in Table 1.

To create a transcriptional fusion of the pitA promoter to lac $Z$, a fragment containing 750 bp of upstream sequence to pitA (MSMEG_1064) was amplified with primers PitA6 and PitA5 and cloned into the BamHI and SphI sites of the low copy-number vector (3-10 copies per cell) pJEM15 [27], resulting in plasmid pAH1. Assays for $\beta$-galactosidase activity were carried out as described previously [13]. Cells of $M$. smegmatis harbouring the empty vector pJEM15 displayed $\beta$-galactosidase activities of less than 2 MU. Statistical analysis of reporter-strain experiments after starvation or stress-exposure was performed using one-way ANOVA followed by a Dunnett's post-test comparison of each sample to the control condition. Data from experiments of the phnD-lacZ and pstS-lacZ constructs in various genetic backgrounds were analyzed by one-way ANOVA followed by Bonferroni post-test comparison of all pairs of data-sets. All statistical analyses were performed using GraphPad Prism 4 software.
To create a construct for markerless deletion of pitA, an $833 \mathrm{bp}$ fragment flanking pitA on the left, including $62 \mathrm{bp}$ coding sequence, was amplified with primers PitA1 and PitA2, and a 1022 bp fragment flanking pitA on the right, including 4 bp coding sequence, was amplified with primers PitA3 and PitA4. The two products were fused by PCRoverlap extension [28], cloned into the SpeI site of the pPR23-derived [29] vector pX33 [13], creating pPitAKO, and transformed into $M$. smegmatis $\mathrm{mc}^{2} 155$. Deletion of pitA was carried out using the two-step method for integration and excision of the plasmid as described previously [20]. Correct integration and excision were confirmed by Southern hybridization analysis as described previously [13]. The deletion resulted in loss of $95 \%$ of the pitA coding sequence, creating strain NP6

For complementation of the pitA deletion, pitA plus 790 bp upstream DNA was PCR amplified with primers cPitAf and CPitAr and cloned as a HindIII fragment into the integrative E. coli/mycobacteria shuttle vector pUHA267 (AgResearch, Wallaceville), creating plasmid pCPitA. Transformation into the pitA mutant resulted in strain NP13. 


\section{Phosphate transport assays}

Strains of $M$. smegmatis were grown to an $\mathrm{OD}_{600}$ of 1 in LBT medium, collected by centrifugation and resuspended to an $\mathrm{OD}_{600}$ between 1.5 and 2 in pre-warmed assay buffer (50 mM MOPS [pH 7.5], $5 \mathrm{mM} \mathrm{MgCl}_{2}, 0.05 \%$ $(\mathrm{w} / \mathrm{v})$ Tween $80,0.4 \%$ glycerol, $\left.37^{\circ} \mathrm{C}\right)$. Initial rates of uptake of [33P]ortho-phosphate (> $92.5 \mathrm{TBq} \mathrm{mmol}^{-1}$; Amersham) were determined over a range of phosphate concentrations between $25 \mu \mathrm{M}$ and $500 \mu \mathrm{M}$ as described previously [13].

\section{Authors' contributions}

SG contributed to design of the study, participated in growth experiments, phosphate transport and reporter gene assays and drafted the manuscript. NE carried out the molecular work and participated in all other experimental aspects. GMC contributed to design of the study, participated in phosphate transport assays and helped to draft the manuscript. All authors read and approved the final manuscript.

\section{Acknowledgements}

The authors would like to thank A. Hümpel for cloning of the pitA deletion and promoter fusion constructs.

\section{References}

I. Wanner BL: Phosphorus Assimilation and Control of the Phosphate Regulon. In Escherichia coli and Salmonella: cellular and molecular biology Volume I. 2nd edition. Edited by: Neidhardt FC, Curtiss R III, Ingraham JL, Lin ECC, Low KB, Magasanik B, Reznikoff WS, Riley M, Schaechter M, Umbarger HE. Washington, DC: ASM Press; 1996:|357-|38|.

2. van Veen HW: Phosphate transport in prokaryotes: molecules, mediators and mechanisms. Antonie Van Leeuwenhoek 1997, 72(4):299-315.

3. van Veen HW, Abee T, Kortstee GJ, Konings WN, Zehnder AJ: Mechanism and energetics of the secondary phosphate transport system of Acinetobacter johnsonii 2 I OA. J Biol Chem 1993, 268(26): 19377-19383.

4. White AK, Metcalf WW: The htx and ptx operons of Pseudomonas stutzeri WM88 are new members of the pho regulon. J Bacteriol 2004, I 86 (I 7):5876-5882.

5. White AK, Metcalf WW: Two C-P lyase operons in Pseudomonas stutzeri and their roles in the oxidation of phosphonates, phosphite, and hypophosphite. J Bacteriol 2004, I 86(I4):4730-4739.

6. Voegele RT, Bardin S, Finan TM: Characterization of the Rhizobium (Sinorhizobium) meliloti high- and low-affinity phosphate uptake systems. J Bacteriol 1997, I 79(23):7226-7232.

7. Metcalf WW, Wanner BL: Involvement of the Escherichia coli phn (psiD) gene cluster in assimilation of phosphorus in the form of phosphonates, phosphite, $\mathbf{P}_{\mathbf{i}}$ esters, and $\mathbf{P}_{\mathbf{i}}$. J Bacteriol 1991, I73(2):587-600.

8. Imazu K, Tanaka S, Kuroda A, Anbe Y, Kato J, Ohtake H: Enhanced utilization of phosphonate and phosphite by Klebsiella aerogenes. Appl Environ Microbiol 1998, 64(I 0):3754-3758.

9. Lefèvre P, Braibant M, de Wit L, Kalai M, Roeper D, Grotzinger J, Delville JP, Peirs P, Ooms J, Huygen K, et al.: Three different putative phosphate transport receptors are encoded by the Mycobacterium tuberculosis genome and are present at the surface of Mycobacterium bovis BCG. J Bacteriol 1997, I 79(9):2900-2906.

10. Braibant $M$, Lefèvre $P$, de Wit L, Ooms J, Peirs $P$, Huygen $K$, Wattiez $\mathrm{R}$, Content J: Identification of a second Mycobacterium tuberculosis gene cluster encoding proteins of an ABC phosphate transporter. FEBS Lett 1996, 394(2):206-212.
II. Collins DM, Kawakami RP, Buddle BM, Wards B], de Lisle GW: Different susceptibility of two animal species infected with isogenic mutants of Mycobacterium bovis identifies phoT as having roles in tuberculosis virulence and phosphate transport. Microbiology 2003, I49(Pt II):3203-32I2.

12. Rifat D, Bishai WR, Karakousis PC: Phosphate Depletion: A Novel Trigger for Mycobacterium tuberculosis Persistence. J Infect Dis 2009, 200(7): I I26-1 I 35.

13. Gebhard S, Tran SL, Cook GM: The Phn system of Mycobacterium smegmatis : a second high-affinity $A B C$-transporter for phosphate. Microbiology 2006, I 52(Pt I I):3453-3465.

14. Cole ST, Brosch R, Parkhill J, Garnier T, Churcher C, Harris D, Gordon SV, Eiglmeier K, Gas S, Barry CE, et al.: Deciphering the biology of Mycobacterium tuberculosis from the complete genome sequence. Nature 1998, 393(6685):537-544.

15. Rosenberg H, Gerdes RG, Chegwidden K: Two systems for the uptake of phosphate in Escherichia coli. I Bacteriol 1977, I 3 I (2):505-5I I.

16. Harris RM, Webb DC, Howitt SM, Cox GB: Characterization of PitA and PitB from Escherichia coli. Journal of bacteriology 200I, I 83(17):5008-50I4.

17. Bardin SD, Voegele RT, Finan TM: Phosphate assimilation in Rhizobium (Sinorhizobium) meliloti : identification of a pit-like gene. J Bacteriol 1998, 180(16):4219-4226.

18. van Veen HW, Abee T, Kortstee GJ, Konings WN, Zehnder AJ: Translocation of metal phosphate via the phosphate inorganic transport system of Escherichia coli. Biochemistry 1994, 33(7): $1766-1770$.

19. van Veen HW, Abee T, Kortstee GJ, Konings WN, Zehnder AJ: Substrate specificity of the two phosphate transport systems of Acinetobacter johnsonii 2 IOA in relation to phosphate speciation in its aquatic environment. I Biol Chem 1994, 269(23): $16212-16216$.

20. Tran SL, Cook GM: The $\mathbf{F}_{\mathbf{I}} \mathbf{F}_{\mathbf{o}}$-ATP synthase of Mycobacterium smegmatis is essential for growth. J Bacteriol 2005, I 87(14):5023-5028.

21. Kay WW, Ghei OK: Inorganic cation transport and the effects on C4 dicarboxylate transport in Bacillus subtilis. Can J Microbiol I 98I, 27(II):II94-I20I.

22. Beard SJ, Hashim R, Wu G, Binet MR, Hughes MN, Poole RK: Evidence for the transport of zinc(II) ions via the pit inorganic phosphate transport system in Escherichia coli. FEMS Microbiol Lett 2000, 184(2):23I-235

23. Cole ST, Eiglmeier K, Parkhill J, James KD, Thomson NR, Wheeler PR, Honore N, Garnier T, Churcher C, Harris D, et al.: Massive gene decay in the leprosy bacillus. Nature 200I, 409(6823): $1007-1011$.

24. Dawson RJ, Hollenstein K, Locher KP: Uptake or extrusion: crystal structures of full ABC transporters suggest a common mechanism. Mol Microbiol 2007, 65(2):250-257.

25. Snapper SB, Melton RE, Mustafa S, Kieser T, Jacobs WR Jr: Isolation and characterization of efficient plasmid transformation mutants of Mycobacterium smegmatis. Mol Microbiol 1990, 4(II): $1911-1919$

26. Sambrook J, Fritsch EF, Maniatis T: Molecular cloning: a laboratory manual. 2nd edition. Cold Spring Harbor, N.Y.: Cold Spring Harbor Laboratory Press; 1989.

27. Timm J, Lim EM, Gicquel B: Escherichia coli-mycobacteria shuttle vectors for operon and gene fusions to lac $Z$ : the pJEM series. J Bacteriol I994, I 76(2I):6749-6753.

28. Ho SN, Hunt HD, Horton RM, Pullen JK, Pease LR: Site-directed mutagenesis by overlap extension using the polymerase chain reaction. Gene 1989, 77(1):51-59.

29. Pelicic V, Jackson M, Reyrat JM, Jacobs WR Jr, Gicquel B, Guilhot C Efficient allelic exchange and transposon mutagenesis in Mycobacterium tuberculosis. Proc Natl Acad Sci USA 1997, 94(20): 10955-10960.

30. Hanahan D, Jessee J, Bloom FR: Plasmid transformation of Escherichia coli and other bacteria. Methods Enzymol 1991, 204:63-II3. 